\title{
Experimental and Simulation Study on Breaking Rock under Coupled Static Loading and Ultrasonic Vibration
}

\author{
Yan Zhao,, ${ }^{1,2}$ Congshan Zhang, ${ }^{1,2}$ Zengzeng Zhang $\mathbb{D D}^{3}{ }^{3}$ Ke Gao $\mathbb{I D}^{1,2}$ Dajun Zhao, \\ Zihang Sun, ${ }^{4}$ Xiaoshu Lv, ${ }^{1,5}$ Yu Zhou, ${ }^{1}$ and Guobing Zhai ${ }^{6}$ \\ ${ }^{1}$ College of Construction Engineering, Jilin University, Changchun, Jilin 130026, China \\ ${ }^{3}$ School of Civil \& Architectural Engineering, Shandong University of Technology, Zibo, Shandong 255000, China \\ ${ }^{2}$ Engineering Research Center of Geothermal Resources Development Technology and Equipment, Ministry of Education, \\ Jilin University, Changchun 130026, China \\ ${ }^{4}$ Beijing Institute of Geological \& Prospecting Engineering, Beijing 100048, China \\ ${ }^{5}$ Department of Civil Engineering, Aalto University, P.O. Box 12100, FIN-02130, Espoo, Finland \\ ${ }^{6}$ Tianjin Sanjian Construction Engineering Co., Ltd, Tianjin 300161, China
}

Correspondence should be addressed to Ke Gao; gaokenm@jlu.edu.cn

Received 15 February 2021; Revised 30 September 2021; Accepted 15 November 2021; Published 5 February 2022

Academic Editor: Francisco Beltran-Carbajal

Copyright (c) 2022 Yan Zhao et al. This is an open access article distributed under the Creative Commons Attribution License, which permits unrestricted use, distribution, and reproduction in any medium, provided the original work is properly cited.

In recent years, ultrasonic vibration rock-breaking technology has aroused great interest in tunnel excavation and underground mineral. To apply this technology to practical engineering, it is necessary to compare the difference between cumulative damage and crack propagation of rock under static load and ultrahigh frequency alternating load. Numerical simulation and laboratory experimental methods were used in this paper to study the damage and fracture characteristics of rock under static loading and ultrasonic vibration. The variation laws of rock infrared temperature characteristics, porosity and compressive strength under different ultrasonic static loads were studied. The discrete element model of rock under ultrasonic vibration was established, and the numerical simulation was carried out by PFC2D software. We designed the ultrasonic rotary drilling device to verify the drilling effect. The process and mechanism of rock fragmentation under static load and ultrasonic vibration load were analyzed from the perspective of energy. Numerical simulation and experimental results showed that the combination of static load and ultrasonic vibration accelerates the failure speed of rock sample. The thermal infrared temperature characteristic test showed that the rock-breaking process under ultrasonic load and static load has three stages: stage I, elastic deformation and the temperature rises linearly; stage II, the development of microcrack and the temperature is further increased uniformly, and stage III, macrobreaking and rock chips falling off, and the temperature fluctuates sharply. There is a minimum threshold value for the promotion of static loading to break rock by ultrasonic vibration. Only when the static load is greater than $200 \mathrm{~N}$, the crack propagation will occur in the rock sample. At this time, with the increase of static load, the crack propagation will further intensify, and the rock-breaking effect is more obvious. Under the same weight on bit (WOB), the penetration of rotary ultrasonic drilling can be increased by $13.93 \% \sim 38.11 \%$ compared with conventional rotary drilling.

\section{Introduction}

In order to meet the increasing demands of social and economic development, people's utilization of underground space and exploitation of underground minerals, petroleum, and other resources are increasing. However, due to the widespread existence of high strength hard rock in underground engineering works such as tunnel and mine excavation, rapid and efficient crushing of hard rock has become a problem that must be solved $[1,2]$. Studies have shown that the high frequency vibration can significantly improve the material removal rate, and the fatigue failure of rock material under the action of cyclic loading can effectively reduce the rock strength and improve the drilling efficiency. The natural frequency of intact compact hard rock is generally above $20 \mathrm{kHz}[3,4]$, which belongs to the 
category of ultrasonic. During the process of drilling, the ultrasonic vibration with the same natural frequency is applied to the rock. When the rock is resonated reasonably, the internal damage will occur quickly, and the vibration intensity will be greatly reduced. The traditional cutting drilling technology combined with ultrasonic vibration can effectively improve the drilling efficiency of hard rock [5].

In recent years, there has been an increasing attention to the mechanism of rock damage and rock failure caused by low frequency vibration [6-8]. As for the rock-breaking mechanism under dynamic load, Zhou et al. carried out dynamic impact tests to investigate the volume fracture and mechanical properties of artificial rock samples produced by $3 \mathrm{D}$-printing (3DP) under high strain rate impact. The results show that the number of defects is inversely proportional to the dynamic compressive strength and tangent modulus, and when the static compression load changes to the dynamic compression load, the tangential modulus of crack and the ratio of fracture initial stress to peak stress increase; in addition, the fracture modes of three-dimensional defects and two-dimensional defects are obviously different [9]. Wiercigroch et al. established the mechanical model of rocking-breaking under ultrasonic vibration and analyzed the feasibility of rock breaking by ultrasonic vibration theoretically [10]. Badescu et al. concluded that drilling speeds were substantially higher with ultrasonic vibration technology compared to conventional rotary drilling [11]. Davison gave a dynamic failure accumulation model for rock, wherein a threshold value exists. The development of rock material failure mainly depends on external loading and the size of the relevant threshold [12]. He et al. indicated that the numbers of cycling in fatigue failure of intact rock and jointed rock decrease with an increase of stress, amplitude, and loading frequency [13]. Erarslan found that the fracture toughness of rock under cyclic loading can be reduced by $43 \%$ by cyclic loading tests [14]. Sdvyzhkova et al. studied the propagation and development characteristics of cracks in rocks under simple harmonic vibration and proposed a crack initiation criterion considering the static stress and dynamic stress in the process of elastic wave propagation in rock. In this criterion, the mutation of the critical length of cracks is regarded as a sign of a dynamic failure of rock. The critical length of initial cracks is determined by the amplitude, frequency, static stress, and rock crack resistance [15]. Jiang et al. performed the sprint Hopkinson pressure bar (SHPB) tests using powder bed and inkjet 3D-printing technique. The experimental results showed that samples containing predefined cracks can be successfully prepared by 3D-printing technology and the mechanical parameters of the $3 \mathrm{D}$ printed material can also be measured [16].

As for the rock fracture mechanism under static load, Zhou et al. conducted static uniaxial compression tests on 3D printed artificial rock samples with defects. The results showed that the defect geometry has a significant influence on the mechanical and fracture behavior of defective samples. The maximum crack growth rate of a single defect sample is higher than that of a double defect sample [17]. Adams and Sines put forward the mechanism of crack propagation of brittle materials under compressive load to provide a model easy to analyze and confirm by experiments and introduced the experimental study of introducing crack propagation into polymethylmethacrylate (PMMA) plastic blocks. The results show that three-dimensional crack extension is relatively complex. Secondary crack extension leads to greater damage than predicted by theoretical analysis [18]. Zhou et al. investigated the process of crack initiation, extension, wrapping, and merging of two preexisting 3D cross-embedded defects in PMMA specimens under uniaxial compression and obtained stress-strain curves for PMMA specimens with 3D cross-embedded defects. The PMMA specimens tested exhibited mainly elastic deformation and brittle damage. The damage mechanism of PMMA specimens was finally revealed by observing the crack emergence and crack consolidation patterns [19]. Ju et al. proposed a new method combining computed tomography and servo-controlled triaxial loading technology to complete the continuous evolution of the $3 \mathrm{D}$ fracture network in coal samples under confining pressure and axial compression load. The results show that when the specimen is subjected to confining pressure, the original cracks of the coal body are closed, and the vertical compression deformation is in the linear elastic stage. Only when the axial compressive load reaches the maximum, the fracture caused by the load will expand significantly [20]. Zhu et al. used 3D-printing (3DP) and 3D numerical simulation to copy the internal defects of rock and study the mechanical and fracture behavior of rock. The proposed method provides a promising means for quantifying, replicating, and visualizing the preexisting defects and microstructure and understanding their effects on rock mechanics and fracture behavior under different loading conditions, which is helpful to better understand the failure mechanism of rock [21]. Fu et al. studied the progressive failure process of specimens under uniaxial and biaxial compression and proposed a new elastic brittle constitutive model. The uniaxial failure process of the specimen is divided into four stages, and the $3 \mathrm{D}$ numerical simulation is carried out by FLAC3D. The results show that the uniaxial and biaxial numerical results of the new method are common with the experimental results [22]. Dyskin et al. studied the mechanism of 3D crack development under uniaxial compression. A number of tests on different transparent cast cement, resin, and mortar samples with a single internal crack of different shapes and sizes produced by different technologies show that the $3 \mathrm{D}$ crack propagation during compression is fundamentally different from the 2D situation [23]. Germanovich et al. discussed the relationship between various mechanisms of tearing or shear fracture and considered the $2 \mathrm{D}$ theoretical model and experimental results used to describe brittle fracture under compression. According to the new experimental results of $3 \mathrm{D}$ crack extension in brittle materials of transparent rock under uniaxial compression, their shortcomings and the significance of the study of $3 \mathrm{D}$ crack propagation characteristics of rock are explained [24].

On the mechanism of rock fragmentation under dynamic static coupling, the experimental results of Li et al. show that siltstone has higher strength under coupled loads. Reference [25]. Li et al. studied the fatigue mechanical 
properties of rock under the combination of static loading and cyclic impact and concluded that the magnitude of confining pressure and axial pressure affects the evolution trend of rock fatigue damage [26]. Zhao et al. studied rock breaking under the static-dynamic coupling, and the results show that the combined loading mode can significantly improve the effect of rock-breaking [27]. Zhou et al. studied the effect of static load on the intrinsic frequency of granite under ultrasonic vibration and obtained that the intrinsic frequency increases logarithmically with the magnitude of the static load [28].

The above research shows that the response of rock to external loadings is greatly influenced by static loadings under static and dynamic coupling loading. Because of the high frequency $(>20 \mathrm{kHz})$ of ultrasonic vibration, the vibration frequencies involved in the above studies is much lower than that of ultrasonic vibrations. At present, under the vibration frequency equivalent to the natural frequency of rock, the research on the influence of static loading on rock strength is still blank. In addition, when ultrasonic vibration is applied to hard rock drilling, the weight on bit (WOB) can be reflected as the static loading of the device, so the static loading is an important factor affecting the effect of ultrasonic vibration on rock fragmentation and its application in the field of hard rock drilling. As the mechanism and conditions of ultrasonic vibration rock breaking are different from those of conventional rock breaking methods. Therefore, the fatigue damage law of rock under the combination of static loading and ultrasonic vibration is thoroughly studied to provide important theoretical support for improving the efficiency of ultrasonic vibration rock breaking, exploring the mechanism of ultrasonic vibration rock breaking and overcoming the technical problems of hard rock drilling.

\section{Discrete Element Simulation}

2.1. Flat-Joint Model and Parameter Calibration. PFC2D software is used to establish the discrete element model of ultrasonic vibration rock breaking by static load $[29,30]$. To solve the problems of the low ratio of unconfined compressive strength to tensile strength and low internal friction angle in PFC2D, a new bonding model called the flat-joint model (FJM) is adopted in this paper.

There are two conceptual surfaces in FJM, and there is a separable interface between them. That is, the interface is divided into several elements. The fracture in each element will cause partial damage to the interface and then produce cracks. The flat joint model rigidly connects the two particles around, and the contact has a skirt structure. Therefore, even after the interface is broken (unbonded), it can continue to provide grain interlocking and rotation resistance, which ensures that the sample has a practical ratio of compressive strength to tensile strength and a reasonable internal friction angle.

After the flat joint contact is installed between the two particles, the force is generated between the contacts, and the fracture and crack of bond contact are further judged according to the force. The normal force is calculated directly, and the shear force is calculated in an increasing way. The calculation formulas of normal stress ${ }^{(e)}$ and shear stress ${ }^{(\mathrm{e})}$ acting on the element are as follows:

$$
\begin{aligned}
\sigma^{(e)} & =\frac{\overline{-F_{e}^{n}}}{A^{(e)}}, \\
\tau^{(e)} & =\frac{\overline{F_{e}^{s}}}{A^{(e)}},
\end{aligned}
$$

where $\overline{F_{e}^{n}}$ and $\overline{F_{e}^{s}}$ are the normal force and shear force acting on the element respectively, and $A^{(e)}$ is the element area.

The normal force and shear force of the flat joint model are updated as follows:

$$
\begin{aligned}
& \bar{F}_{e}^{n}=\int_{e} \sigma d A, \\
& \bar{F}_{e}^{s}=k_{s} A^{(e)} \delta_{s},
\end{aligned}
$$

where $K_{s}$ is the tangential stiffness, $\delta_{s}$ is the tangential displacement. The obtained formula is used to update the normal stress and shear stress in equation (1).

When the stress state update is completed, the judgment of whether the crack occurs or not begins. The tensile strength is defined as $\sigma_{b}$. When the normal stress value is greater than $\sigma_{b}$, the element breaks and tensile cracks occur.

For shear strength, there are two cases: Unbonded state and bonded state.

\subsubsection{Unbonded State}

$$
\tau_{r}= \begin{cases}-\sigma^{(e)} \tan \varphi_{r}, & \sigma^{(e)}<0, \\ 0, & \sigma^{(e)}=0,\end{cases}
$$

where $\tau_{r}$ is the residual friction strength, $\varphi_{r}$ is the residual friction angle, if satisfied $\tau^{(\mathrm{e})} \leq \tau_{r}$. Then the shear stress value is stable $\tau^{(\mathrm{e})}$. Otherwise, the shear stress will exceed the limit of friction shear strength and contact slip will occur.

\subsubsection{Bonding State}

$$
\tau_{c}=c_{b}-\sigma^{(e)} \tan \varphi_{b},
$$

where $c_{b}$ is bond cohesion, $\varphi_{b}$ is the local friction angle, if satisfied $\tau^{(\mathrm{e})} \leq \tau_{r}$. Then the shear stress value is stable $\tau^{(\mathrm{e})}$. Otherwise, the shear strength limit will be exceeded. The bond breaks and shear cracks occur.

In order to make the mechanical parameters consistent with the actual granite samples, the process of parameter correction needs to be carried out. It is an important process of PFC simulation to correct meso parameters by using the macroproperties obtained from rock basic mechanical tests. Only after this process is completed can the established model be used in the next step.

Firstly, the microcontact parameters are calibrated according to the macrocharacteristics of the material, including effective modulus, particle normal/shear stiffness ratio, flat joint tensile strength, and cohesion. The corresponding macroscopic properties include young's modulus, 
Poisson's ratio, UCS, and tensile strength. In addition to the microscopic parameters, the microstructure (e.g., slit contact used to simulate the initial crack) also affects the macroscopic characteristics of the established model, such as the initial damage of rock samples.

Uniaxial compression tests (UCS) and Brazilian splitting tests (BTS) were carried out to calibrate meso parameters. When the uniaxial compression test simulation is carried out, the loading speed of the top wall and bottom wall is $0.05 \mathrm{~m} / \mathrm{s}$, while for the Brazilian test simulation, the loading speed is $0.0075 \mathrm{~m} / \mathrm{s}$. In this case, the specimen can be regarded as a quasistatic specimen. In the Brazilian test simulation, the width of the loaded wall is equal to twice the average particle size. At the same time, in order to ensure the smoothness of the Brazilian split sample, a circular wall with a resolution equal to 0.08 is used to generate the sample. The corrected microparameters and rock mechanical forms are shown in Tables 1 and 2.

2.2. Boundary Conditions and Simulation Results. The numerical model is the same size as the physical sample, and the particle number is 10 627. The ultrasonic vibration is loaded through the reciprocating motion of the wall, and the wall motion form satisfies the sine function. The application frequency of ultrasonic is $20 \mathrm{kHz}$. In the numerical simulation solution process, the ultrasonic vibration loading cycle is set to 400,000 steps, and the solution time is $5.0 \times 108 \mathrm{~s}$. Figure 1 shows the discrete element model and the applied boundary conditions.

Figure 2 shows the crack distribution characteristics of ultrasonic vibration rock samples under static loading of $100-500 \mathrm{~N}$. It can be seen that the internal crack of rock is mainly distributed at the interface between rock sample and ultrasonic loading wall, and the crack growth is mostly concentrated at both ends. The increase of static loading can promote the crack network in the rock to extend downward, resulting in a large increase in the number of cracks. Comparing the experimental results with the numerical simulation results, it is found that the generation, propagation, and penetration of microcracks in the numerical simulation are consistent with the experimental results.

The time evolution curve of crack number of rock samples under different static loadings is shown in Figure 3. The internal cracks of the model grow in stages with time. When the static loading is $100 \mathrm{~N}$, the number of cracks is small and the growth is gentle. This shows that the ultrasonic vibration causes cracks in the model and the $100 \mathrm{~N}$ static loading has little influence on it. When the static load is $200 \mathrm{~N}$, the number of cracks under ultrasonic vibration is significantly higher than that under $100 \mathrm{~N}$ static load. When it reaches 100000 steps, the number of cracks increases slightly, when it reaches 300000 steps, the number of cracks increases rapidly, and finally, the number of the cracks reaches 350 . The main reason is that the stress in the model caused by the static loading makes the particles more likely to contact fracture and cracks under the vibration. When the static loading is higher than $200 \mathrm{~N}$, the crack growth rate is greatly increased as the model crack number appears multiple stepwise growths and the increase is obvious. The reason is that the stress caused by the increase of static loading in the model is increased and the random distribution is more likely to promote the penetration of the cracks caused by ultrasonic vibration [32], resulting in a large number of cracks in the model.

\section{Rock Breaking Experiment under Static Loading and Ultrasonic Vibration}

To investigate the mechanism of rock crushing effect under the combination of static loading and ultrasonic vibration, the infrared time-space evolution test, rock porosity test, and uniaxial compressive strength test of rock under the combination of static loading and ultrasonic vibration are carried out in this paper.

3.1. Experiment Conditions. Granite is a hard rock widely distributed in the Earth's crust. According to the requirements conventional mechanical performance test of rock, standard granite samples as shown in Table 3 are selected.

Figures 4 and 5 show the main experimental equipment, including infrared thermal imager and ultrasonic vibration loading device $[3,33]$. The components of the ultrasonic are as follows: (1) a driving power: this supplies power to the transducer by converting the $50-60 \mathrm{~Hz}$ current to a higher power and frequency $(15-100 \mathrm{kHz}),(2)$ a vibration generator: high frequency electric current is converted into mechanical vibration energy by using it, (3) an amplitude transformer: connect the fixed transducer and the tool head, this device amplifies the vibrations from the transducer and sends them to the tool head, (4) the tool head: transfer the pressure and the mechanical energy to the sample [34]. A vertical static loading was applied on the top of the bracket, while a $20 \mathrm{kHz}$ ultrasonic dynamic loading was exerted by the vibration generator. The FLIR-E60 thermal imaging camera produced by FLIR was used. Noncontact measurement can be achieved and the labeling of the temperature in the specified area can be displayed. The infrared imager is connected to the computer by a data cable and then tested after debugging. The table shows the other performance parameters of the device.

3.2. Experimental Procedure. The granite samples were placed in the limit ring, making its upper surface contact with the vibration head of the ultrasonic vibration device, and the static loadings of $100 \mathrm{~N}, 200 \mathrm{~N}, 300 \mathrm{~N}, 400 \mathrm{~N}$, and $500 \mathrm{~N}$ were applied, respectively. The ultrasonic driving power was turned on to perform the ultrasonic fatigue loading. The test was stopped after 3 minutes.

Rock is a kind of composite material containing microcracks, microholes, and other microdefects. The voids in rock that are not filled by solid materials are the pores of rock. Porosity is the ratio of the pore volume of rock to the surface volume of rock. It can be calculated as follows: 
TABLE 1: Microproperties of balls and contacts [31].

\begin{tabular}{lcc}
\hline & Properties & Value \\
\hline Ball properties & Ball density $\left(\mathrm{kg} / \mathrm{m}^{3}\right)$ & 2650 \\
& Ball radius $(\mathrm{mm})$ & $0.28 \pm 0.04$ \\
\hline & Bonded element fraction, $\varphi_{B}$ & 0.9 \\
& Slit element fraction, $\varphi_{r}$ & 0.1 \\
Ball-ball contact properties & Stiffness ratio & 1.8 \\
& Effective moduli $(\mathrm{GPa})$ & 40 \\
& Mean and standard deviation bond tensile strength, $\sigma_{b}(\mathrm{Mpa})$ & $11.6 \pm 0.39$ \\
& Mean and standard deviation bond cohesion, $C_{b}(\mathrm{Mpa})$ & $41.5 \pm 1.53$ \\
\hline \multirow{2}{*}{ Ball-wall contact properties } & Local friction angle, $\phi_{b}\left({ }^{\circ}\right)$ & 4 \\
& Residual friction angle, $\phi_{r}\left({ }^{\circ}\right)$ & 10 \\
\hline
\end{tabular}

TABle 2: Rock properties from experiments and simulations [31].

\begin{tabular}{lcc}
\hline Property & Experiment results & Simulation results \\
\hline Young's modulus E (GPa) & $52.3 \pm 12.2(n=10)$ & $47.6 \pm 0.231(n=10)$ \\
Poisson's ratio & $0.26 \pm 0.05(n=10)$ & $0.235 \pm 0.03(n=10)$ \\
Uniaxial compressive strength (UCS) (MPa) & $116 \pm 19(n=10)$ & $115.7 \pm 1.5(n=10)$ \\
Brazilian tensile strength (BTS) (MPa) & $8.1 \pm 1.5(n=10)$ & $8.15 \pm 0.092(n=10)$ \\
\hline
\end{tabular}

*Note that, in the experiments, $n$ denotes the number of samples undergone the compression or Brazilian tests, while in PFC, it denotes the number of samples with different bond strength distributions.

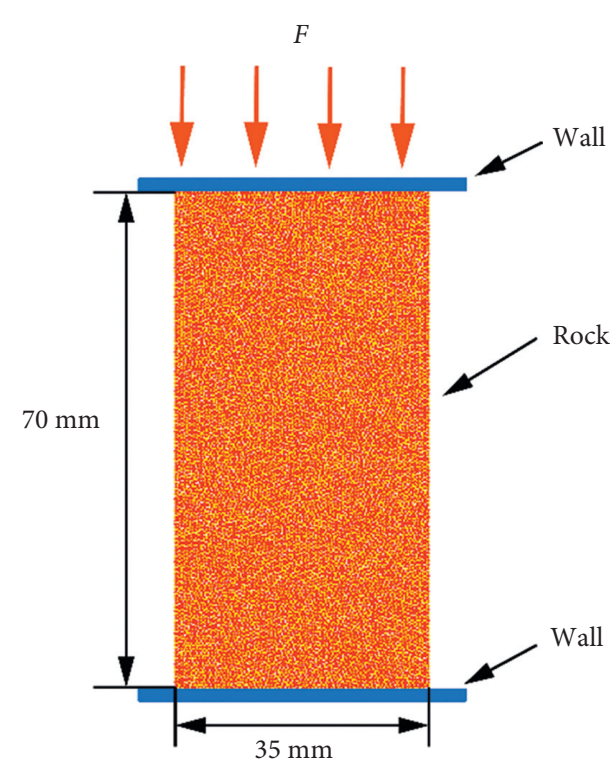

FIGURE 1: Rock model and boundary conditions.

$$
e=\frac{V_{e}}{V_{t}},
$$

where $e$ is porosity, $V_{e}$ is effective pore volume, and $V_{t}$ is rock surface volume.

When the ultrahigh frequency vibration frequency is consistent with the natural frequency of rock, it can cause great damage to the rock in a short time and make the microcracks in the rock expand and develop rapidly. The most intuitive phenomenon is the increase of pores after the ultrasonic vibration test. Therefore, porosity is an important index for determining rock fragmentation.
In order to reduce the influence of sample anisotropy and inhomogeneity on the test results, 5 groups of parallel tests were conducted under each static loading condition, and a total of 25 groups of ultrasonic rock fragmentation tests were carried out. Each sample was processed by ultrasonic vibration device, and then the porosity and compressive strength of the sample after vibration were tested by MesoMR23-060H-I type nuclear magnetic resonance analyzer and WEW-1000D hydraulic universal testing machine. While vibrating the rock, the real-time dynamic measurement of rock sample temperature was carried out with an infrared thermal imager.

\section{Results and Discussion}

4.1. Rock Fragmentation. The device shown in Figure 5 is used to carry out ultrasonic vibration indoor experiments on rock samples. The rock crushing results are shown in Figure 6. With the increase of static load, the damage degree of rock vibration surface gradually increases. When the static pressure is $500 \mathrm{~N}$, the damage degree of the rock working surface is the most serious, which is mainly reflected in a large number of small rock cuttings and the large increase of damage volume after the test. Under the condition of no static pressure, it can be seen from the picture that there is only a slight damage trace on the vibrating end face of the rock sample. When the applied static pressure is $300 \mathrm{~N}$, it can be seen that the crushing volume at the contact between the rock vibration surface and the ultrasonic transducer tool head begins to increase. When the applied static pressure is $400 \mathrm{~N}$, the rock sample is obviously damaged, accompanied by a small amount of large debris, but the damage degree is weaker than that of the rock sample under $500 \mathrm{~N}$ static pressure. When the static pressure reaches $500 \mathrm{~N}$, the 

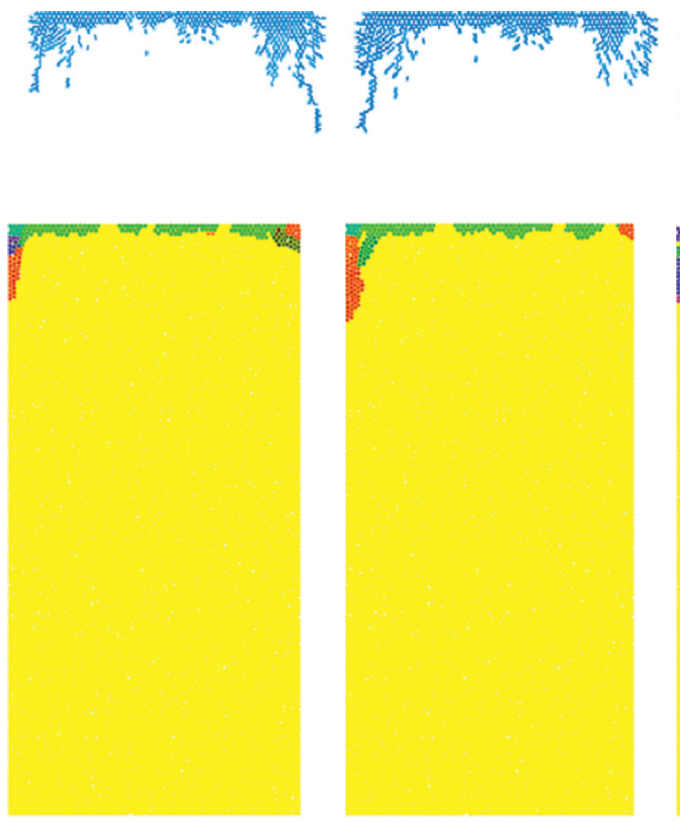

$100 \mathrm{~N}$

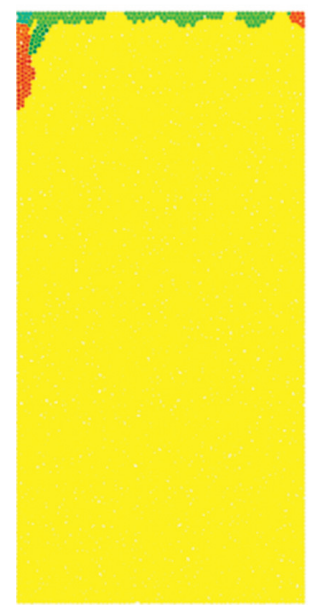

$200 \mathrm{~N}$
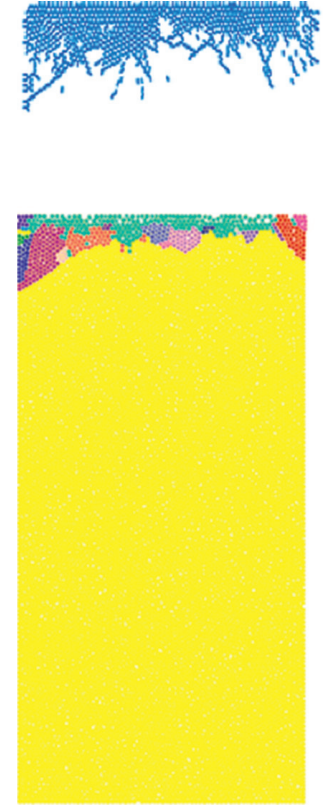

$300 \mathrm{~N}$
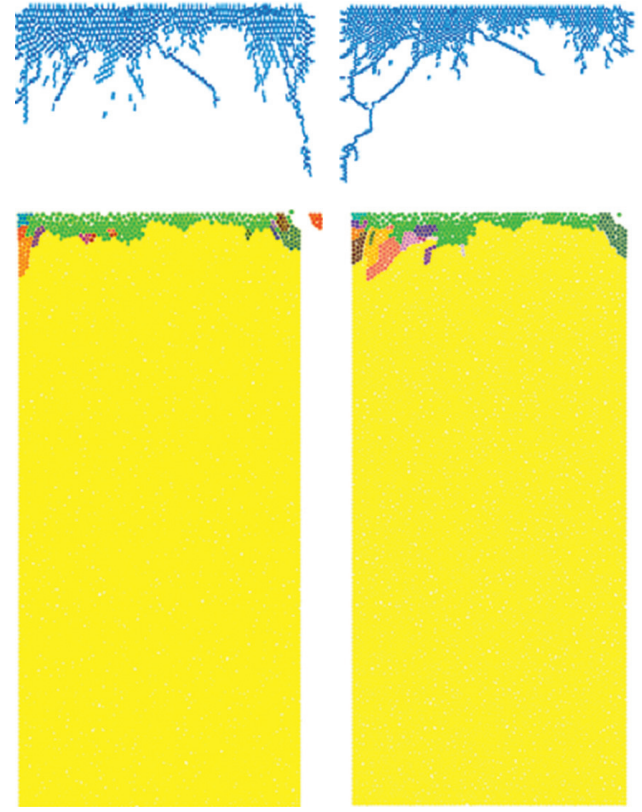

$400 \mathrm{~N}$

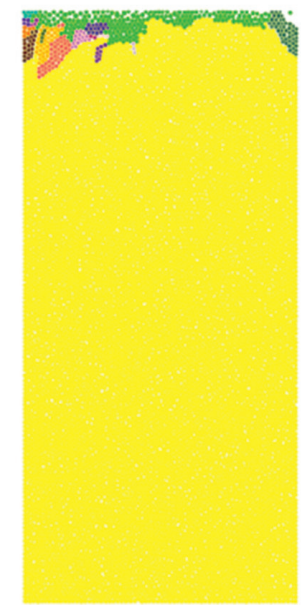

$500 \mathrm{~N}$

FIGURE 2: Rock crack distribution characteristics and failure morphology.

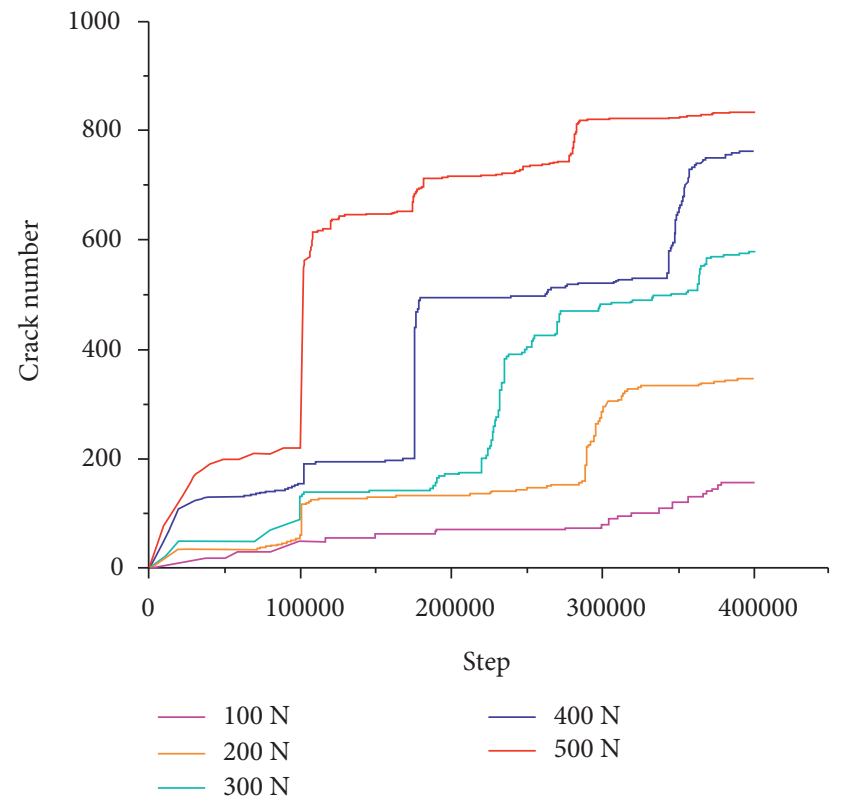

FIgURE 3: Evolution curve of crack number with time.

damage degree of rock is the most severe. This also corresponds to the numerical simulation results in Figures 2 and 3.

From the above description, the static pressure has a great impact on the effect of ultrasonic vibration rock crushing, and under the action of $0 \sim 500 \mathrm{~N}$ static pressure, the greater the static pressure applied to the rock, the better the crushing effect. This shows that in a certain range, the energy density applied to the rock increases with the increase of pressure. The more plastic strain energy absorbed by the
TABle 3: Rock sample parameters.

\begin{tabular}{lc}
\hline Rock sample parameters & Value \\
\hline Diameter $(\mathrm{mm})$ & $\phi 35$ \\
Height $(\mathrm{mm})$ & 70 \\
Nonparallelism $(\mathrm{mm})$ & $<0.02$ \\
Uniaxial compressive strength $(\mathrm{MPa})$ & 83.98 \\
\hline
\end{tabular}

rock for crack generation and crushing, the lower the fatigue strength of the rock, the greater the crack propagation rate and damage rate, and the higher the crushing efficiency.

4.2. Thermal Infrared Radiation Characteristics. The thermal infrared radiation characteristic test of rock under ultrasonic vibration is based on the thermal infrared imaging flaw detection technology. It dynamically detects the temperature field of rock surface in the process of ultrasonic vibration under different static loading conditions in real-time to obtain the evolution law of the temperature field of rock. In addition, it also reflects the evolution process of stress in rock. Figure 7 is the spatial and temporal evolution map of the rock surface temperature field. The infrared thermal imager recorded the evolution process of the rock surface temperature field $(0 \mathrm{~s}-180 \mathrm{~s})$ during the whole process of a rock sample from integrity to fragmentation after ultrasonic vibration under $300 \mathrm{~N}$ static loading. The temperature field on the surface of the rock sample shows good uniformity without the application of ultrasonic vibration. At the beginning of vibration, the white temperature field cloud image appears in the contact area of the tool head and rock. The vibration time increases, the rock temperature also increases. At $80 \mathrm{~s}$, the rock began to break up at the edge, and the debris fell. On the whole, the temperature field on the 


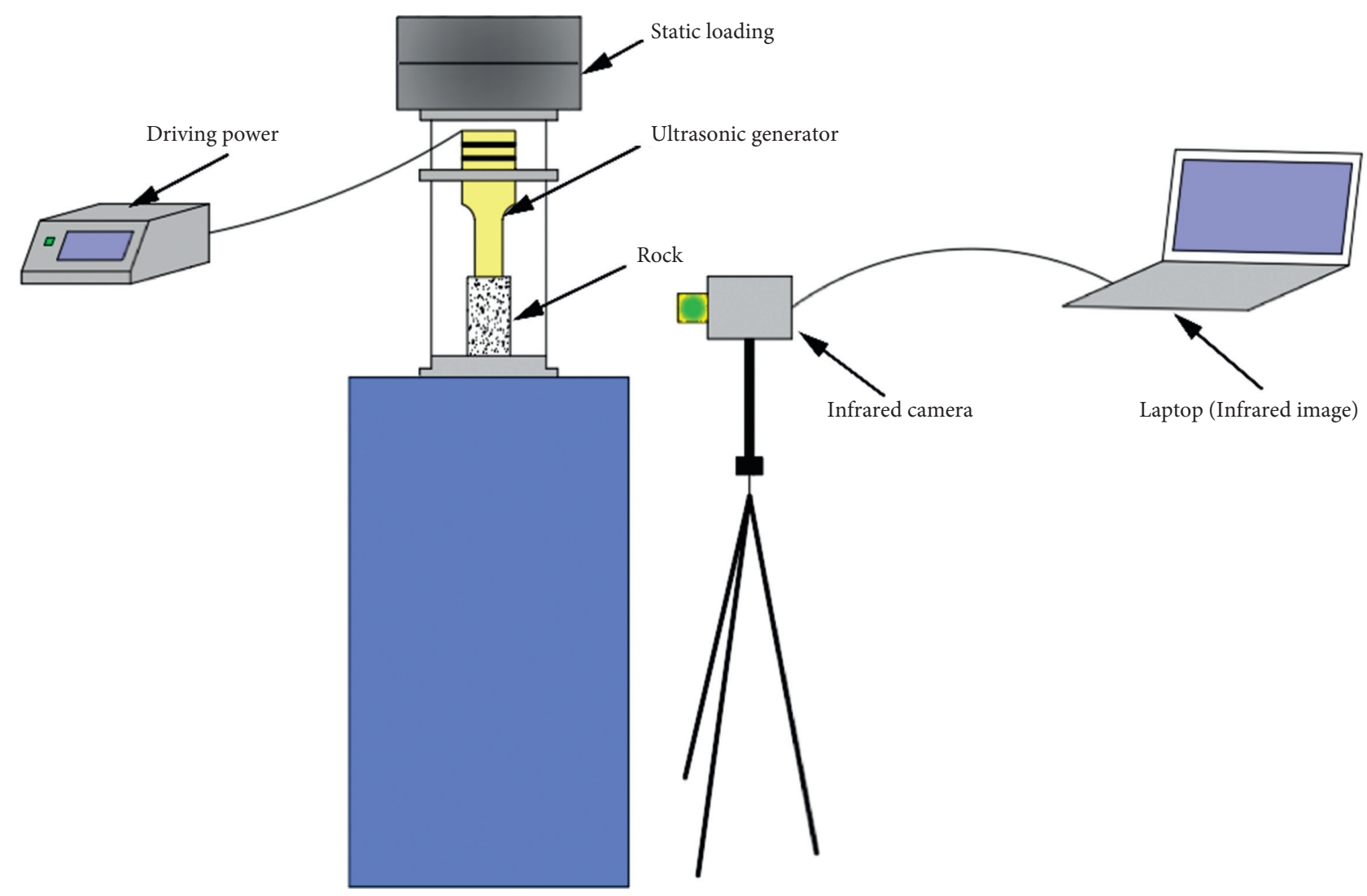

FIgURE 4: Experimental system diagram.
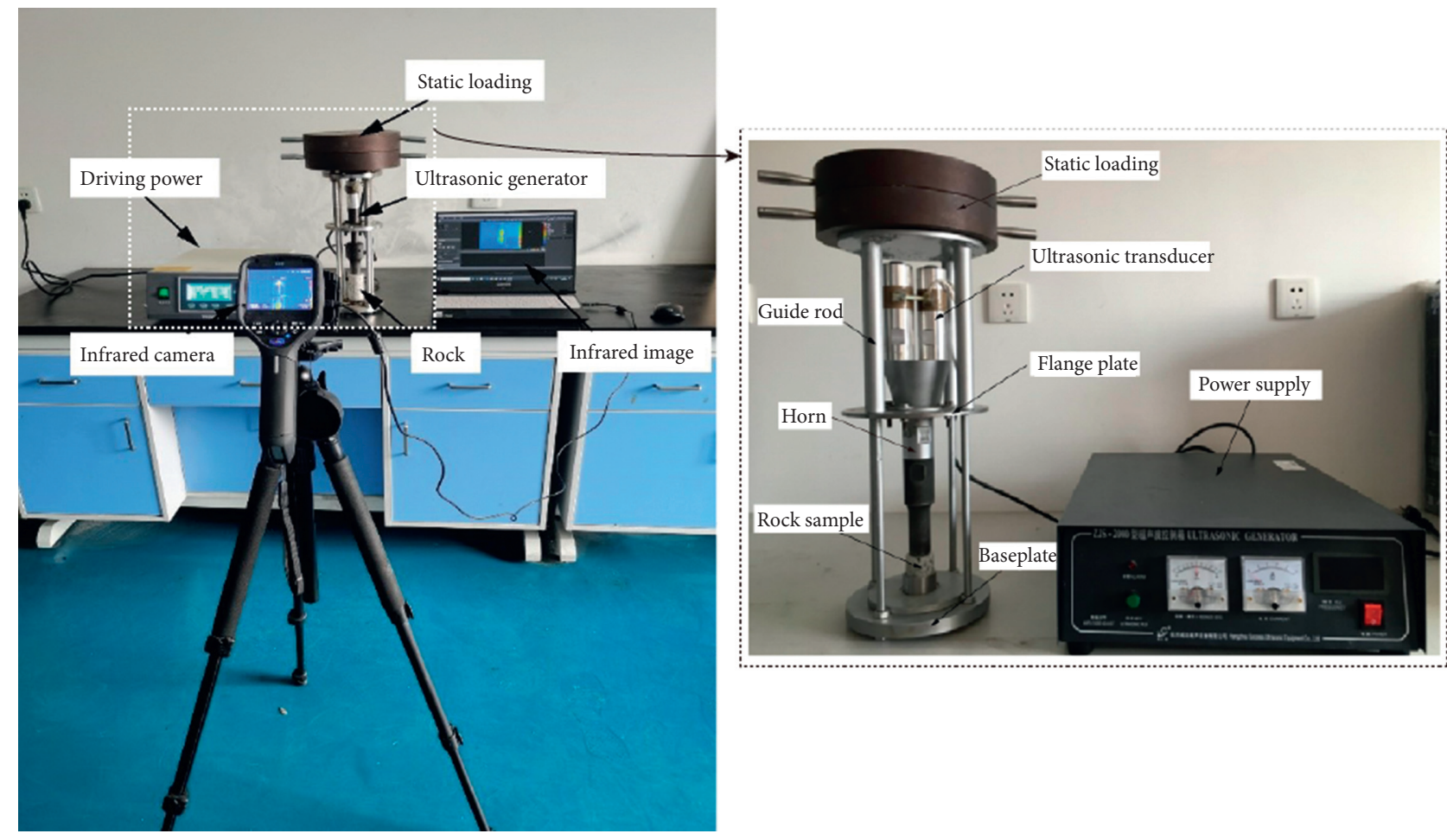

FIgure 5: Physical map of ultrasonic vibration test. 
TABLE 4: Equipment parameters.

\begin{tabular}{|c|c|c|}
\hline Equipment & Working parameters & Value \\
\hline \multirow{3}{*}{ Ultrasonic generator } & Working current (A) & 2 \\
\hline & Power range $(\mathrm{W})$ & $0-1600$ \\
\hline & Max. static loading $(\mathrm{N})$ & 600 \\
\hline \multirow{9}{*}{ FLIR-E60 infrared thermal imager } & Image resolution (pixels) & $320 \times 240$ \\
\hline & Spatial resolution (mard) & 1.36 \\
\hline & Thermal sensitivity $(\mathrm{C})$ & $<0.05$ \\
\hline & Continuous digital zoom (times) & $1-4$ \\
\hline & Measurements range $(\mathrm{C})$ & $-20^{\circ} \mathrm{C}-120 / 0^{\circ} \mathrm{C}-650$ \\
\hline & Built-in digital camera (million pixels) & 3.1 \\
\hline & Max. speed of image acquisition (frames/s) & 30 \\
\hline & Field of view ( ) & $25 \times 19$ \\
\hline & Detection wavelength interlude $(\mu \mathrm{m})$ & $7.3-13$ \\
\hline
\end{tabular}

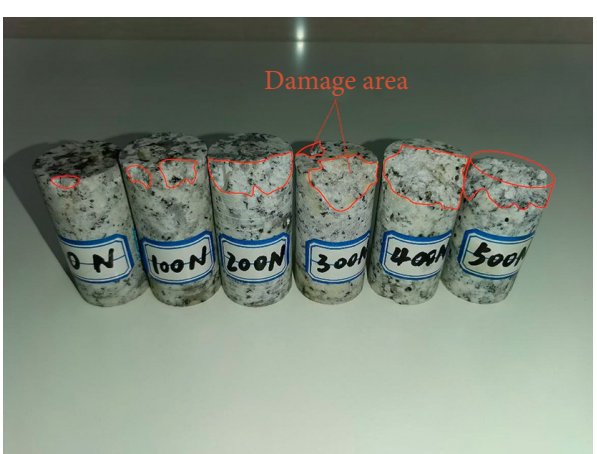

Figure 6: Fragmentation of granite under ultrasonic load under different pressures.

rock surface is always in a state of dynamic change under the action of ultrasonic vibration, and the vibration time increases, the temperature of the entire rock surface is constantly rising, but the temperature growth of the rock at different locations is different. Generally, the point far away from the top of the rock sample has a relatively small temperature value and obvious gradient changes. The highest temperature point is always located in the fracture zone at the top of the sample, and the lowest temperature point is near the bottom of the sample.

Figure 8 shows the infrared temperature field of rock surface under different static loadings at the end of vibration (180 s). It can be seen that, at $0 \mathrm{~N}$ and $100 \mathrm{~N}$, there is almost no debris falling off on the experimental platform. Debris appears at $200 \mathrm{~N}$, the most debris falling off at $500 \mathrm{~N}$, and the volume of debris is also large. Under the ultrasonic vibration, the static loading promotes the generation, expansion, and penetration of rock microdefects inside and around mineral crystals into macrocracks. When the macrocracks in the rock accumulate continuously and reach the critical point of breaking, the rock will appear macro-broken. The occurrence of macroscopic cracks caused the samples to exhibit macroscopic fragmentation and debris shedding, and the macrodamage mainly occurs in the top edge area of the rock sample. Therefore, the static loading intensifies the damage degree of rock under ultrasonic vibration.

Figure 9 shows the temperature-time curve of the fixed monitoring point under the action of the whole ultrasonic wave under different static loads (the detection point is $5 \mathrm{~mm}$ from the top of the rock). According to the temperature-time curve of the fixed monitoring point, the temperature curves of $0 n$ and $100 \mathrm{~N}$ are the same, and they all show a linear growth trend with time. The corresponding temperature curves under the four static loads of $200 \mathrm{~N}, 300 \mathrm{~N}, 400 \mathrm{~N}$, and $500 \mathrm{~N}$ are consistent, which can be divided into three stages: the first stage: linear increase of temperature; the second stage: slow increase of temperature; the third stage: sharp fluctuation of temperature. The smaller the static load is, the smaller the temperature change of the monitoring point is.

4.3. Porosity Experiment Results. Figure 10 reflects the variation of porosity with the increase of static loading. The porosity of each group of samples after ultrasonic vibration is higher than the corresponding initial porosity. The curve shows a gentle first and then rising trend with the increase of static loading. When the static loading is in the range of $100 \mathrm{~N}-200 \mathrm{~N}$, the curve of porosity change is approximately straight line. It can be considered that the combination of static loading and ultrasonic vibration under this condition can hardly cause damage to the interior of rock samples. Within the range of $200 \mathrm{~N}-300 \mathrm{~N}$, the porosity curve increases rapidly with the increase of pressure, and the increase range of porosity is high. It shows that under the combined action of static loading and ultrasonic vibration, microcracks in rock samples begin to appear and develop, and damage accumulates. Static loading can greatly promote the relative increase of porosity of rock samples. With the increase of static loading, internal cracks of rock samples develop rapidly and damage accumulates rapidly. From $300 \mathrm{~N}-400 \mathrm{~N}$, the slope of the curve decreases slightly but still increases rapidly with the increase of static loading. The increase of porosity increases with the increase of static loading. In this range, the increase of pressure continues to increase the rate of crack generation and development in rock samples under ultrasonic vibration. The crack initiation and propagation speed of the rock sample are faster, and the damage degree increases with the increase of static loading. The results show that the pore growth rate of rock samples is directly proportional to the static load in the range of $400 \mathrm{~N}-500 \mathrm{~N}$. Although the change trend of porosity gradually slows down, the increase of static loading still promotes the relative increase of the generation and development speed of microcracks in 


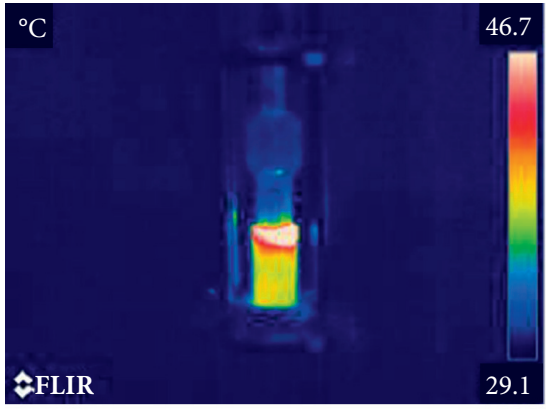

$20 \mathrm{~s}$

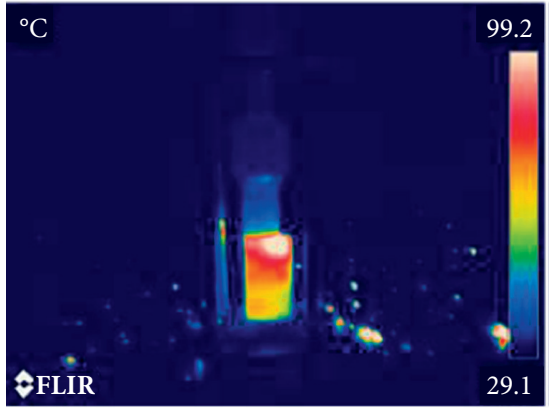

$80 \mathrm{~s}$

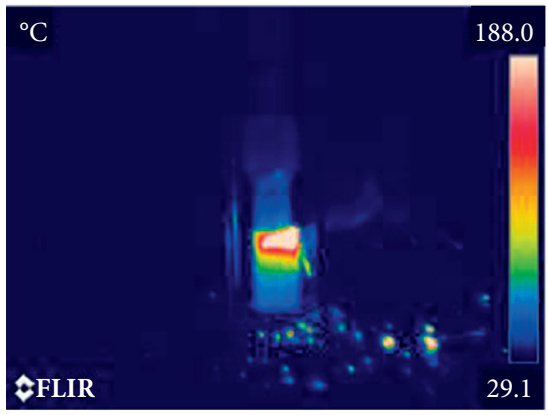

$140 \mathrm{~s}$

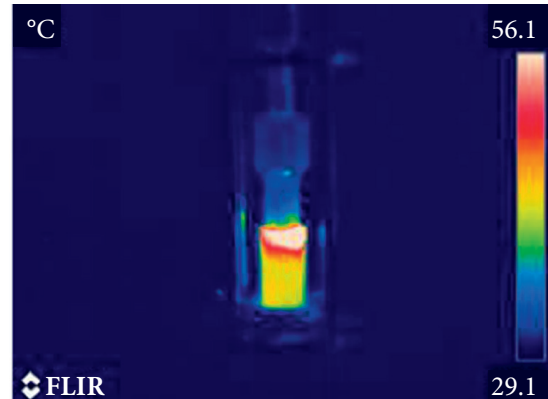

$40 \mathrm{~s}$

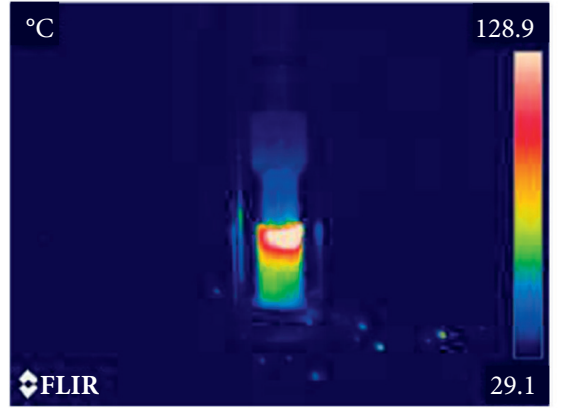

$100 \mathrm{~s}$

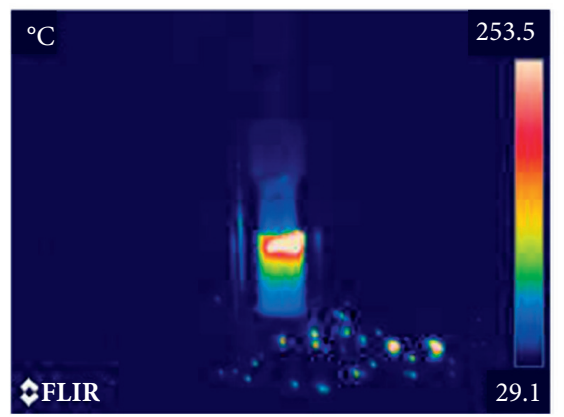

$160 \mathrm{~s}$

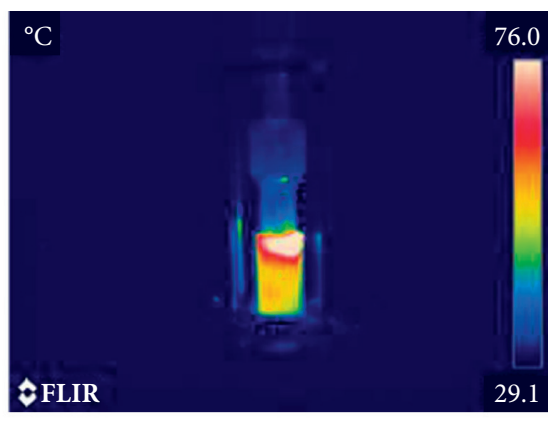

$60 \mathrm{~s}$

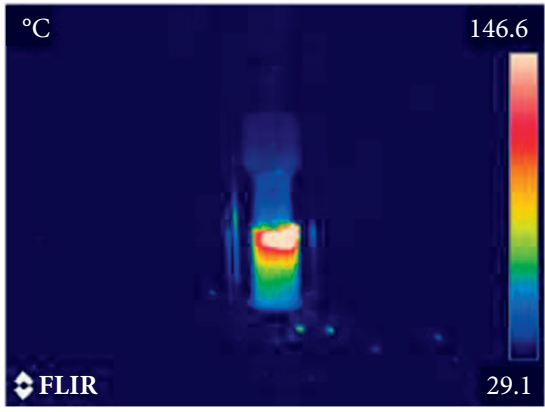

$120 \mathrm{~s}$

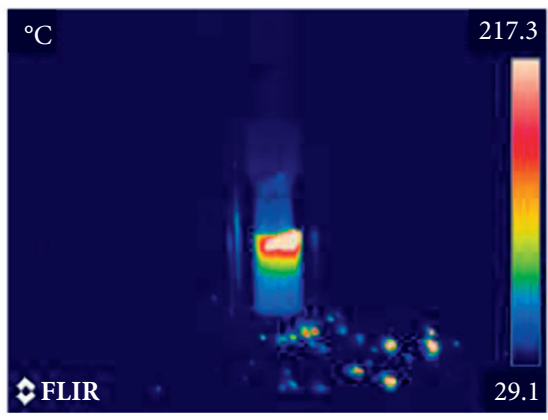

$180 \mathrm{~s}$

FIGURE 7: Spatiotemporal evolution map of rock surface temperature field $(300 \mathrm{~N})$.

rock samples under ultrasonic vibration, and the damage degree of rock samples still increases with static loading.

Therefore, under the condition of ultrasonic vibration, the promoting effect of static loading on the increase of pore size increases with the increase of static loading; the slope of the curve varies with the change of static loading, which indicates that the static loading has different effects on the generation and development of cracks in granite under ultrasonic vibration. Furthermore, it can be concluded that the static loading has different effects on the generation and development of cracks under high frequency vibration. It affects the effect of breaking granite by ultrasonic vibration.

4.4. Uniaxial Compression Experiment Results. In order to detect the change of compressive strength of rock samples after vibration under different pressure conditions, the influence of pressure on the effect of ultrasonic vibration rock breaking is compared and analyzed. The uniaxial compressive strength of rock is measured by dns300 electronic universal testing machine, and 5 rock samples after ultrasonic vibration under $100-500 \mathrm{~N}$ static pressure are measured. In addition, the rock compressive strength test of the nonvibration group shall be carried out to detect the original compressive strength value of the rock. There are also 5 rock samples of the nonvibration group. During the test, place the rock sample in the pressure plate of the universal testing machine, and align the upper and lower bearing plates without eccentricity. Then, load at the rate of $0.5 \mathrm{MPa} / \mathrm{s}$, and record the failure load and the phenomena in the experiment.

After ultrasonic vibration, the samples show different failure modes in uniaxial compression tests with different static loadings. As shown in Figure 11, the failure modes of rock samples in uniaxial compression test are as follows: A is the initial fracture mode of rock samples without ultrasonic vibration, b-f is the static loading of $100-500 \mathrm{~N}$, and the uniaxial fracture mode of rock samples after 6 minutes of ultrasonic vibration. From Figure 11, we can clearly see that the rock sample without ultrasonic vibration is a mixture of brittle fracture and shear fracture, and the fracture direction distributes uniformly around it. 


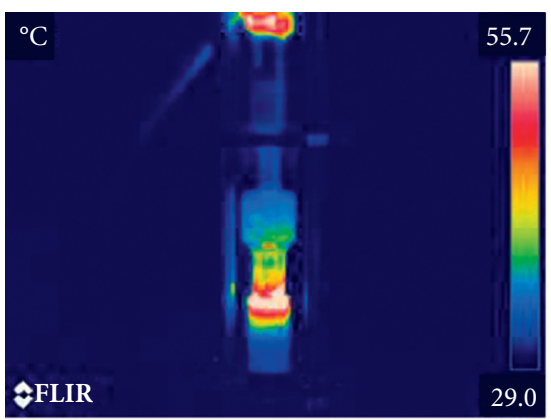

$0 \mathrm{~N}$

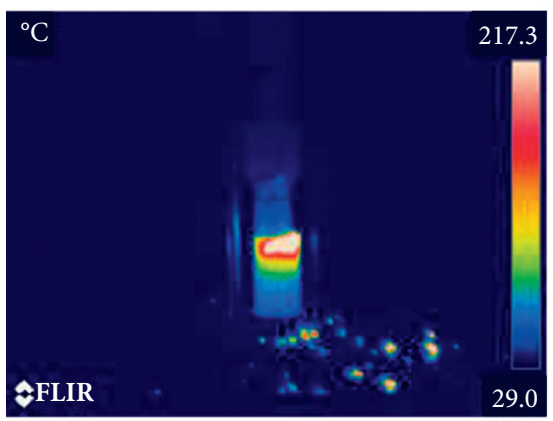

$300 \mathrm{~N}$

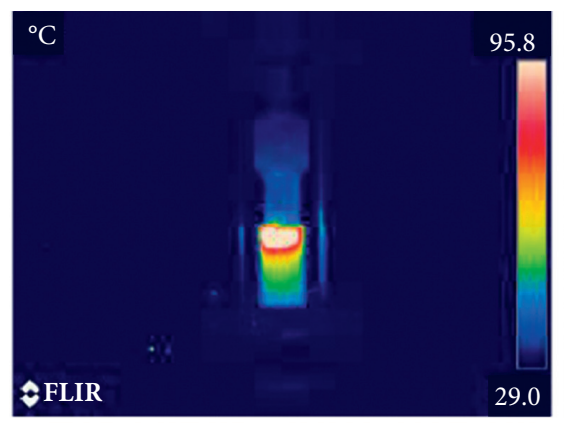

$100 \mathrm{~N}$

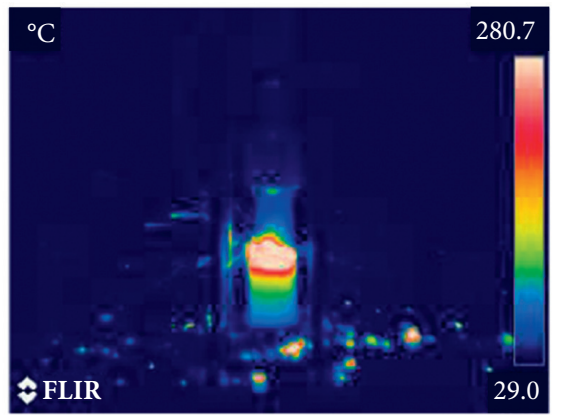

$400 \mathrm{~N}$

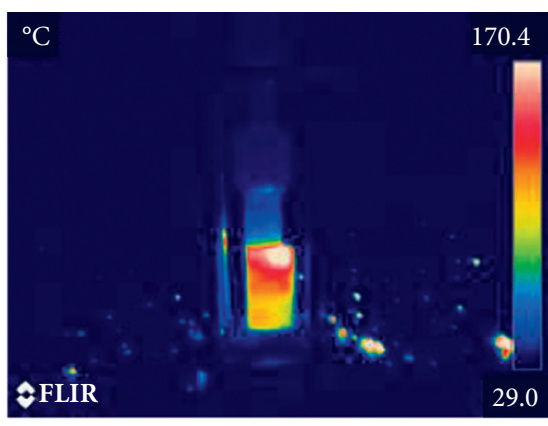

$200 \mathrm{~N}$

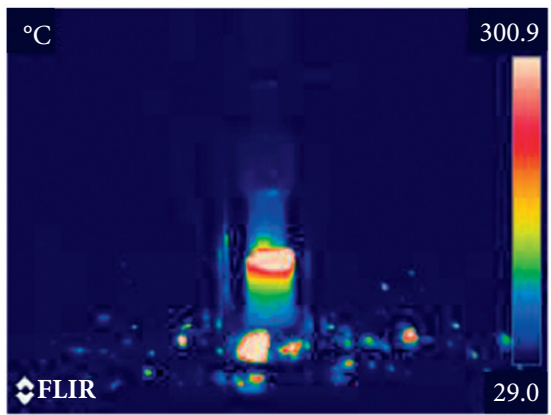

$500 \mathrm{~N}$

Figure 8: Temperature field of rock surface under different static loadings.

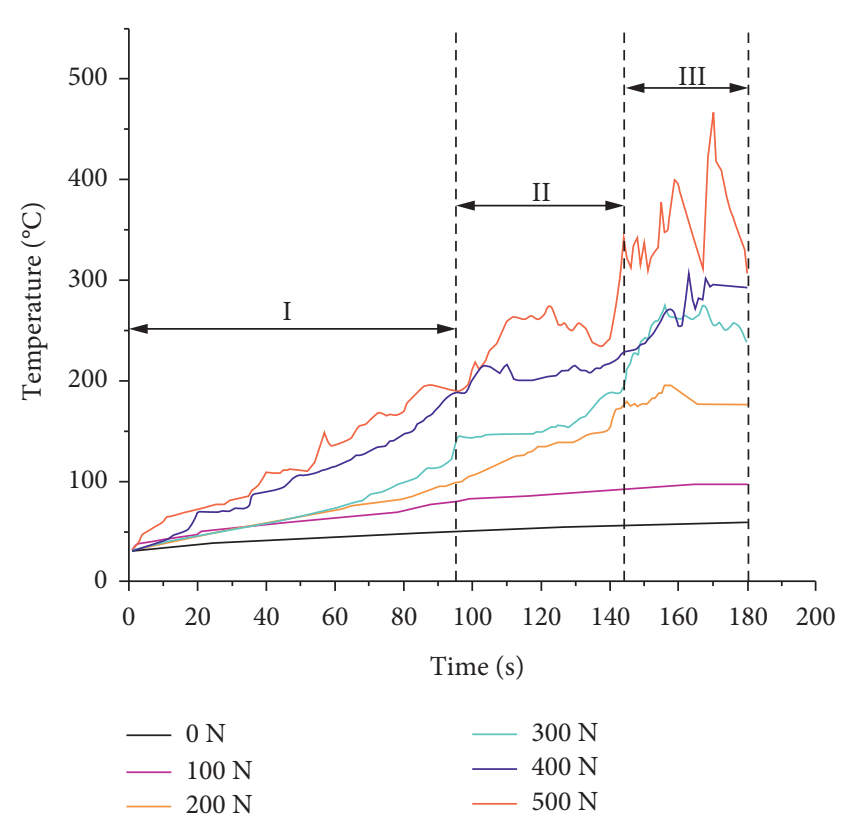

FIGURE 9: Temperature curves of fixed monitoring points of rock.

The failure mode of rock samples after ultrasonic vibration under uniaxial compression is a mixture of brittle tension and shear slip, and the brittle failure mode is more obvious than that of rock samples without ultrasonic vibration. And the number of fractured blocks is more than that of rock samples without ultrasonic vibration, and the greater the static loading, the greater the degree of fragmentation.

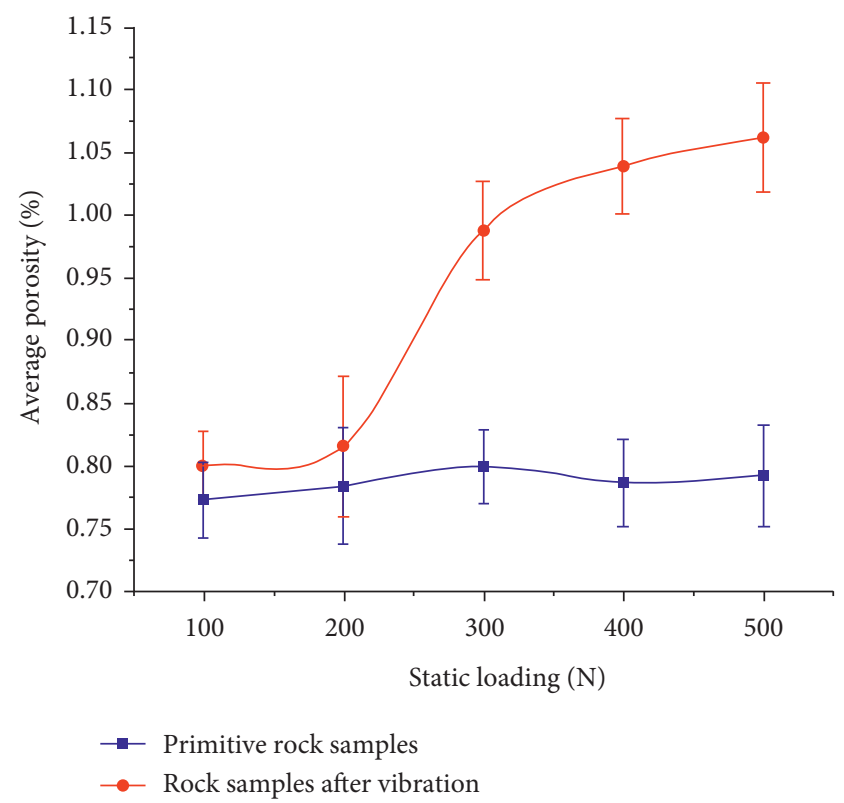

Figure 10: Porosity curve of samples with static loading.

This shows that the combination of static loading and ultrasonic vibration enhances the brittleness of rock samples.

Figure 12 shows the compressive strength of granite under different static loading. Under different static loadings, the compressive strength of each group of rock samples decreased compared with the original average compressive strength after ultrasonic vibration with a frequency of 

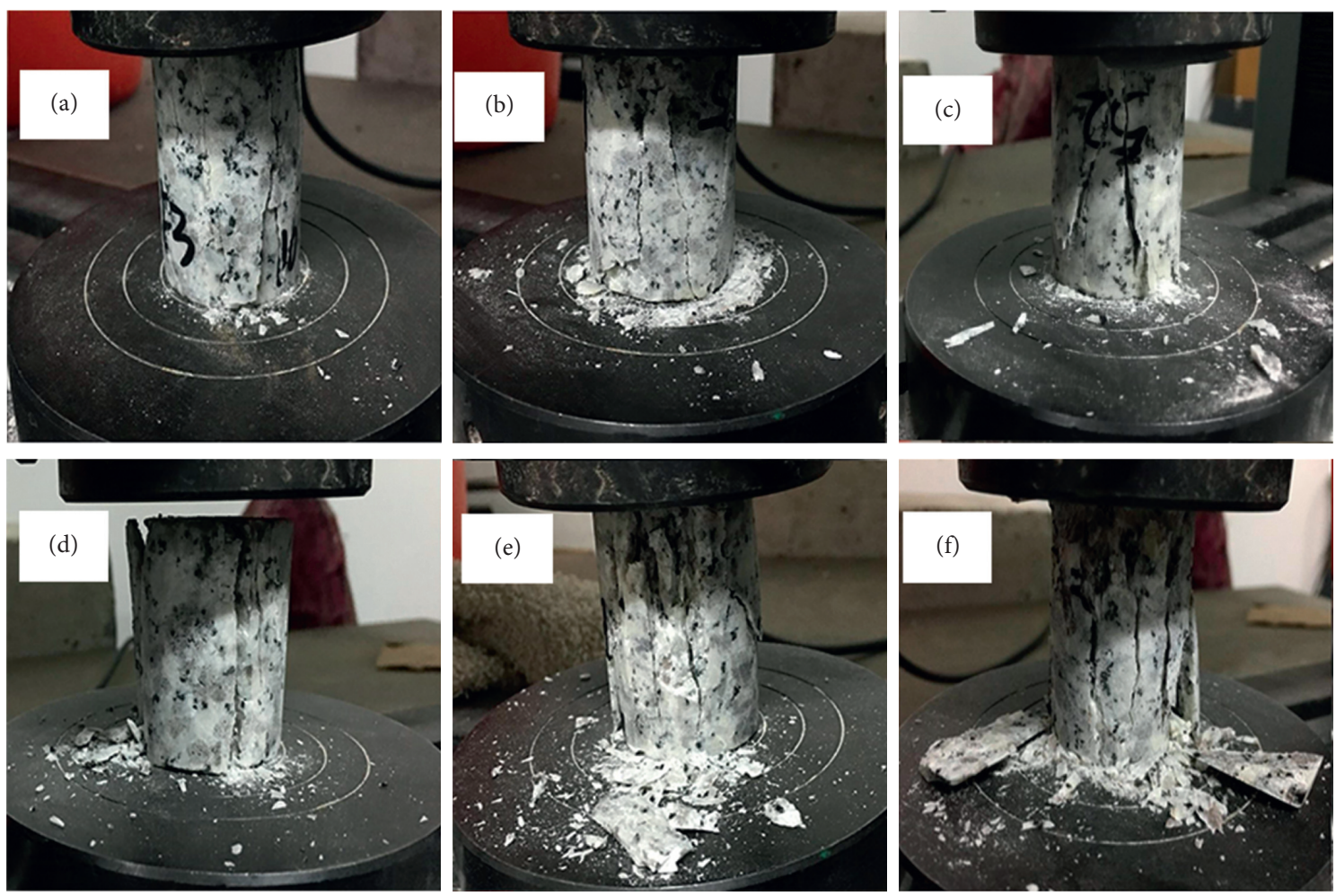

FIGURE 11: Crushing state of samples in compressive strength test ((a) without ultrasonic vibration. (b) (c), (d) (e), and (f) are applied with $100 \mathrm{~N}, 200 \mathrm{~N}, 300 \mathrm{~N}, 400 \mathrm{~N}$, and $500 \mathrm{~N}$ static loadings combined with ultrasonic vibration, respectively).

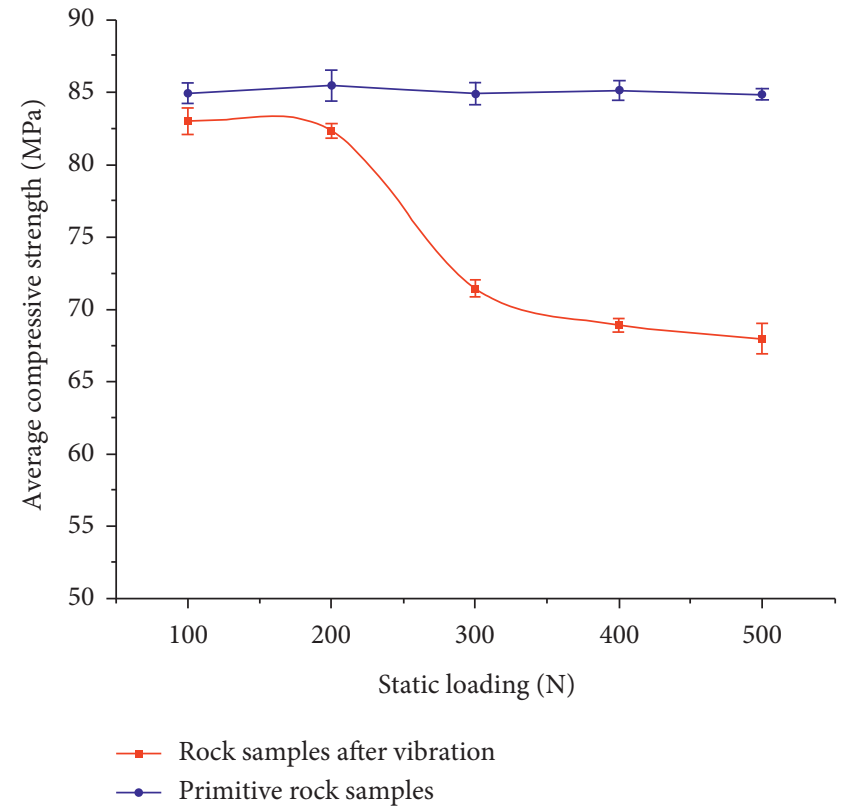

FIGURE 12: Compressive strength curve of samples with static loading.

$20 \mathrm{kHz}$. When the static loading is less than $200 \mathrm{~N}$, the change of compressive strength of granite after ultrasonic vibration is very small. The combination of static loading and ultrasonic vibration has little effect on the rock sample, which indicates that the stress threshold for internal crack

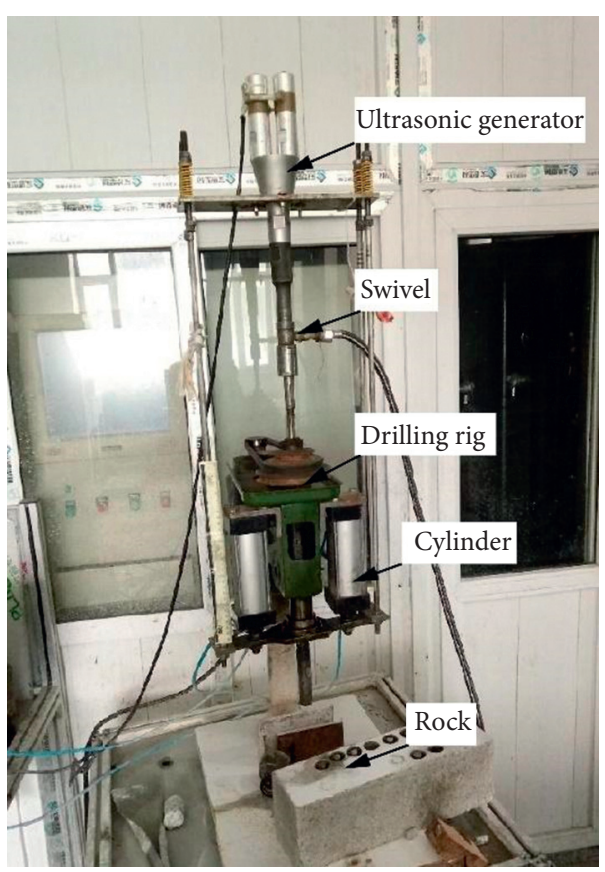

FIGURE 13: Rotary ultrasonic drilling equipment.

propagation has just been reached at this time. There is a static loading threshold between $200 \mathrm{~N}-300 \mathrm{~N}$. When the static loading exceeds the threshold. The compressive strength suddenly decreases rapidly. The ultrasonic vibration starts to promote the generation and propagation of cracks 
in rock samples, and the internal damage of rock samples increases with the increase of static loading. When the loading is between $300 \mathrm{~N}-500 \mathrm{~N}$, the trend of the decrease of compressive strength slows down slightly, and the ultrasonic vibration still promotes the steady development of microcracks in rock samples.

\section{Rotary Ultrasonic Drilling Experiment}

5.1. Experiment Description. Through previous experiments and numerical simulation studies, it is known that the combination of static loading and ultrasonic vibration can promote the damage and fracture of rock. Then, we applied the ultrasonic vibration to the microdrilling test platform, which was mainly composed of three parts: rotary system, pressurization system, and circulation system. The ultrasonic transducer was installed on the top of the faucet of the microdrilling rig, and the faucet was redesigned and processed. The modified ultrasonic vibration drilling equipment and main parameters were shown in Figure 13 and Table 4. According to the previous conclusion, the static loading is too small, and the combination of static loading and ultrasonic vibration has little effect on the rock sample. In order to more clearly show the difference of $\mathrm{WOB}$ on the penetration rate of rotary ultrasonic drilling and conventional drilling, we choose a larger WOB as much as possible $(600 \mathrm{~N}, 750 \mathrm{~N}$, $900 \mathrm{~N}, 1050 \mathrm{~N}, 1200 \mathrm{~N})$.

5.2. Experiment Results. The penetration rate of rotary ultrasonic drilling and conventional rotary drilling is shown in Figure 14. It can be seen that the average penetration rate of both drilling methods increases linearly with WOB. However, under the same WOB, the penetration rate of loading ultrasonic vibration is higher than that of conventional rotary drilling, which is enough to show that ultrasonic vibration can improve drilling efficiency. Figure 15 shows the relationship between the increase of penetration rate and WOB. With the increase of WOB, the increase of penetration rate increases first and then slows down. The maximum increase of penetration rate is $38.11 \%$ when the WOB is $1050 \mathrm{~N}$.

\section{Discussion}

The experiimental and simulation results show that the fracture first occurs at the top edge of the rock, which is due to the fatigue failure of the rock surface caused by the periodic vibration force, resulting in the stress concentration in the weak area (edge) of the rock and gradually damage accumulation and cracking. When the crack propagation reaches a certain level, the rock suddenly breaks. The development of crack affects the mechanical properties of rock, which leads to a significant reduction of rock strength. Different static loadings can make the existing microcracks of rock open or close differently degrees and form stress with different action forms and sizes at the microcracks, resulting in different degrees of microcrack propagation or penetration [33]. Therefore, the larger the static loading, the more
TABLE 5: Rotary ultrasonic drilling equipment parameters.

\begin{tabular}{lccc}
\hline $\begin{array}{l}\text { Speed }(\mathrm{r} / \\
\mathrm{min})\end{array}$ & $\begin{array}{c}\text { WOB } \\
(\mathrm{N})\end{array}$ & $\begin{array}{c}\text { Inner diameter } \\
(\mathrm{mm})\end{array}$ & $\begin{array}{c}\text { Outer diameter } \\
(\mathrm{mm})\end{array}$ \\
\hline 780 & $0-1500$ & 14 & 30 \\
\hline
\end{tabular}

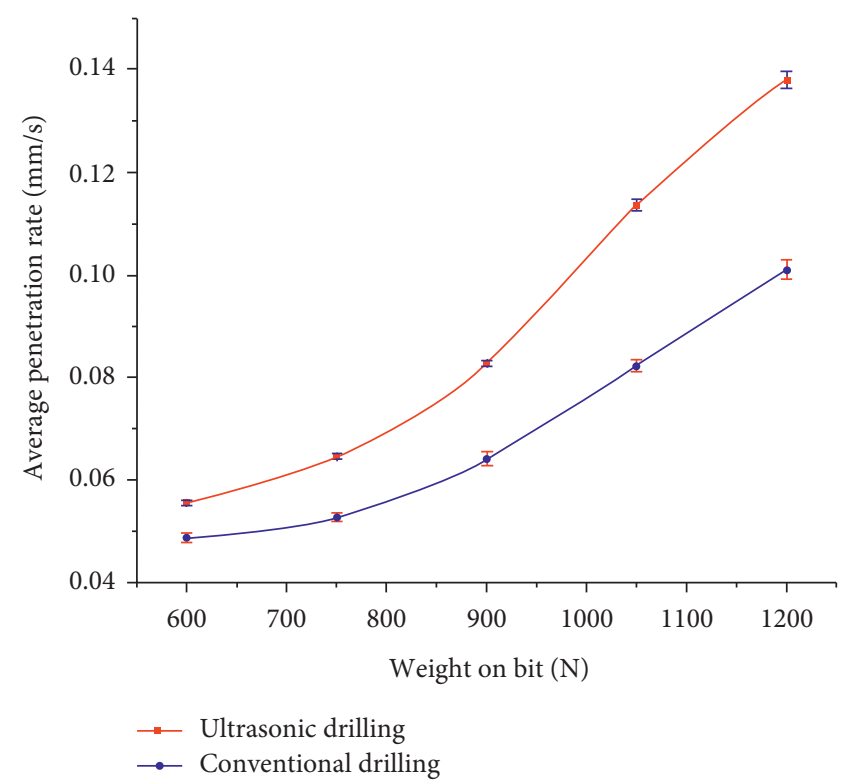

FIgURE 14: The relationship between WOB and average ROP.

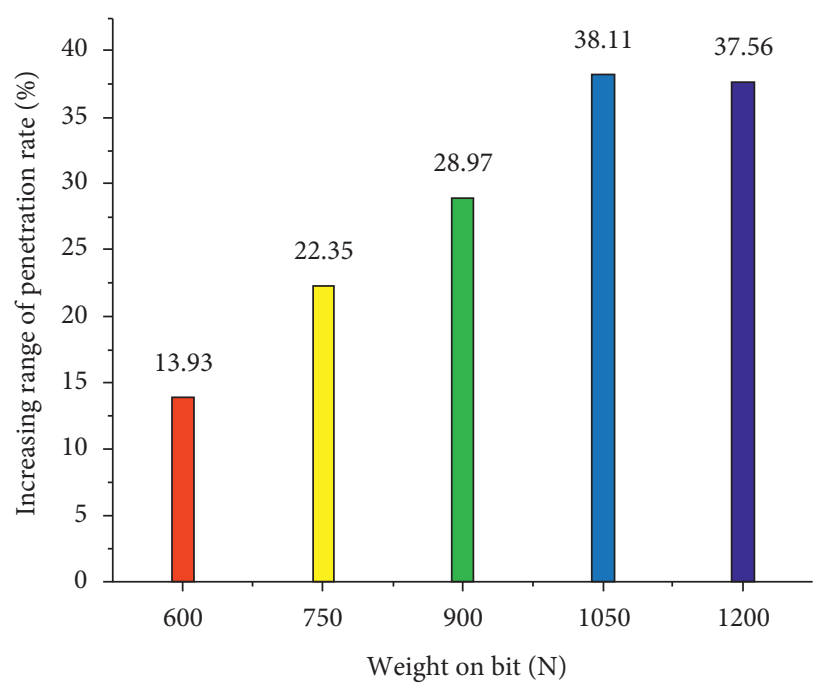

Figure 15: The relationship between WOB and the increase of ROP.

cracks generated inside the rock sample by ultrasonic vibration, the faster the internal cracks expand, and the more serious the fracture degree of the rock sample.

The infrared temperature anomaly before rock failure is important precursor information of rock failure and instability. Therefore, it is very important to capture and 
distinguish the infrared precursor when rock is broken for using thermal infrared imaging equipment to study rock's damage and failure process [35]. In this paper, the obtained temperature-time curves under different static loadings have the following typical stage characteristics: stage I, the temperature increases linearly with time; stage II, the temperature increases slowly; stage III, the temperature fluctuates greatly. The thermoelastic effect in stage I is the main reason for the increase in rock temperature. During the loading process, the temperature of the detection point increases linearly due to the accumulation of energy. In stage II, the increasing temperature is due to the heat generated by the crack friction. After the end of the elastic deformation stage, microfracture and yield will occur in the rock, and a large number of microcracks will be produced in the rock. Under the combined action of normal stress and shear stress, friction will be produced on both sides of each microcrack, resulting in a large amount of friction heat. The continuous action of ultrasonic loading leads to micro-crack propagation and penetration, forming macrocracks, and finally leading to rock failure. The sharp fluctuations in the temperature-time curve during stage III are due to the large energy expenditure accompanying the macroscopic fracture penetration and dislodgement of rock particles [36, 37].

The energy during ultrasonic vibration loading is closely related to rock breaking. We analyze the influence of static loading on the efficiency of ultrasonic vibration breaking rock from the perspective of energy dissipation. During the cutting process of the bit, the energy is mainly converted into elastic, plastic and dissipative energy, in which the elastic energy is stored in the rock and released completely with the recovery of rock deformation. When the elastic limit of rock is exceeded, the plastic properties accumulate. When the stress limit of the material is exceeded, the damage occurs, and part of the input energy is converted into dissipation energy $[26,27]$. When ultrasonic vibration is introduced, the incident energy and friction heat are increased. In the combination of static loading and ultrasonic vibration, when the vibration force is constant, the existence of static loading increases the stress value, increases the total incident energy, and increases the propagation of stress waves in rock, so the plastic strain energy is converted to crack propagation increases, the more plastic deformation energy absorbed by rock, the faster the cracks are generated and broken, the shorter the fatigue life, and the higher the rock breaking efficiency. Moreover, the transmission of stress waves generated by high frequency vibration will cause the friction heat of the cracks in the rock, which will increase the temperature of the rock, and the existence of static loading will aggravate the friction heat. The thermal expansion coefficient and thermal elastic properties of the rock-forming mineral components in granite are different. Mineral particles may expand unevenly thermally or undergo phase changes at high temperatures, causing internal stress and cracks and thermal damage in granite. Therefore, the high temperature generated by friction heat will further promote the internal thermal damage of rock and deteriorate the physical and mechanical parameters of the rock.

\section{Conclusions}

In this paper, the cumulative evolution of rock damage under the combination of static loading and ultrasonic vibration is studied. The rock surface infrared radiation temperature, porosity, and compressive strength are recorded by ultrasonic vibration breaking granite under different static loadings. From the perspective of energy, the mechanism of rock breaking under the combined action of static loading and ultrasonic vibration is analyzed, which has important theoretical and practical significance for exploring the dynamic fatigue mechanical characteristics of rock and efficient rock breaking.

(1) The experiment and simulation results show that the combination of static loading and ultrasonic vibration can promote rock breaking. Static loading aggravates the generation and development of internal cracks in the rock, increases porosity, and reduces compressive strength of rock, thereby promoting the degree of rock damage and destruction under ultrasonic vibration.

(2) There is a minimum threshold value for the promotion of static loading to the rock breaking by ultrasonic vibration. When the static loading is less than $200 \mathrm{~N}$, the influence of ultrasonic vibration on the crack propagation in rock is weak. Therefore, the surface temperature of the rock sample increases slowly, and the changes of porosity and compressive strength of the rock sample are little before and after vibration. Only when the static loading is greater than $200 \mathrm{~N}$, the crack initiation and propagation will take place inside the rock, and the larger the static loading is, the more obvious the fracture effect of the rock is.

(3) The thermal infrared temperature characteristics test shows that the rock breaking process can be divided into three stages: stage I, elastic deformation, linear increase in temperature, stage II, the development of microcracks, the temperature further increases uniformly, and stage III, macrobreaking and rock chips falling off, and the temperature fluctuates sharply.

(4) Ultrasound vibration can effectively improve drilling efficiency. Under the same WOB, the penetration rate of loading ultrasonic vibration rotary drilling is higher than that of conventional rotary drilling. With the increase of WOB, the increase of penetration rate increases first and then slows down, and the increase range is between $13.93 \%$ and $38.11 \%$.

\section{Data Availability}

The data used to support the findings of this study are available from the corresponding author upon request.

\section{Conflicts of Interest}

The authors declare that they have no conflicts of interest. 


\section{Authors' Contributions}

Yan Zhao reviewed and edited the manuscript and took part in data curation. Congshan Zhang provided software and took part in data curation. Zengzeng Zhang was responsible for methodology, software, and investigation. Ke Gao acquired funding, supervised the study, and reviewed and edited the manuscript. Dajun Zhao and Xiaoshu Lv reviewed and edited the manuscript and supervised the study. Zihang Sun reviewed and edited the manuscript and provided experiment equipment. Yu Zhou provided software and took part in data curation. Guobing Zhai took part in methodology and provided experiment equipment.

\section{Acknowledgments}

This research was funded by the National Natural Science Foundation of China (Grant nos. 42172345 and 41972324) and the Engineering Research Center of Geothermal Resources Development Technology and Equipment, Ministry of Education, Jilin University.

\section{References}

[1] Q. Geng, Z. Wei, H. Meng, F. J. Macias, and A. Bruland, "Freeface-Assisted rock breaking method based on the multi-stage tunnel boring machine (TBM) cutterhead," Rock Mechanics and Rock Engineering, vol. 49, no. 11, pp. 4459-4472, 2016.

[2] G. L. Cavanough, M. Kochanek, J. B. Cunningham, and I. D. Gipps, "A self-optimizing control system for hard rock percussive drilling," IEEE/ASME Transactions on Mechatronics, vol. 13, no. 2, pp. 153-157, 2008.

[3] S. Yin, D. Zhao, and G. Zhai, "Investigation into the characteristics of rock damage caused by ultrasonic vibration," International Journal of Rock Mechanics and Mining Sciences, vol. 84, pp. 159-164, 2016.

[4] A. V. Lebedev, V. V. Bredikhin, I. A. Soustova, A. M. Sutin, and K. Kusunose, "Resonant acoustic spectroscopy of microfracture in a Westerly granite sample," Journal of Geophysical Research: Solid Earth, vol. 108, no. B10, 2003.

[5] P. Fernando, M. Zhang, and Z. Pei, "Rotary ultrasonic machining of rocks: an experimental investigation," Advances in Mechanical Engineering, vol. 10, no. 3, 2018.

[6] W. Li, T. Yan, S. Li, and X. Zhang, "Rock fragmentation mechanisms and an experimental study of drilling tools during high-frequency harmonic vibration," Petroleum Science, vol. 10, no. 2, pp. 205-211, 2013.

[7] L. Sun, C. Bu, P. Hu, and B. Xia, "The transient impact of the resonant flexible drill string of a sonic drill on rock," International Journal of Mechanical Sciences, vol. 122, pp. 29-36, 2017.

[8] E. Pavlovskaia, D. C. Hendry, and M. Wiercigroch, "Modelling of high frequency vibro-impact drilling," International Journal of Mechanical Sciences, vol. 91, pp. 110-119, 2015.

[9] T. Zhou, J. Zhu, and H. Xie, "Mechanical and volumetric fracturing behaviour of three-dimensional printing rock-like samples under dynamic loading," Rock Mechanics and Rock Engineering, vol. 53, no. 6, pp. 2855-2864, 2020.

[10] M. Wiercigroch, J. Wojewoda, and A. M. Krivtsov, "Dynamics of ultrasonic percussive drilling of hard rocks," Journal of Sound and Vibration, vol. 280, no. 3-5, pp. 739-757, 2005.

[11] M. Badescu, J. Hasenoehrl, and Y. Bar-Cohen, "Percussive Augmenter of Rotary Drills (PARoD)," Sensors And Smart
Structures Technologies For Civil Mechanical and Aerospace Systems, vol. 8692, p. 13, 2013.

[12] L. Davison and A. L. Stevens, "Continuum measures of spall damage," Journal of Applied Physics, vol. 43, no. 3, pp. 988-994, 1972.

[13] M. He, N. Li, Y. Chen, and C. Zhu, "Strength and fatigue properties of sandstone under dynamic cyclic loading," Shock and Vibration, vol. 2016, Article ID 9458582, 8 pages, 2016.

[14] N. Erarslan, "Microstructural investigation of subcritical crack propagation and Fracture Process Zone (FPZ) by the reduction of rock fracture toughness under cyclic loading," Engineering Geology, vol. 208, pp. 181-190, 2016.

[15] O. Sdvyzhkova, Y. Golovko, and D. Klymenko, "Effect of harmonic oscillations on a crack initiation in the rock mass," Naukovyi Visnyk Natsionalnoho Hirnychoho Universytetu.vol. 4, pp. 13-18, 2017.

[16] C. Jiang, G.-F. Zhao, J. Zhu, Y.-X. Zhao, and L. Shen, "Investigation of dynamic crack coalescence using a gypsum-like 3D printing material," Rock Mechanics and Rock Engineering, vol. 49, no. 10, pp. 3983-3998, 2016.

[17] T. Zhou, J. B. Zhu, Y. Ju, and H. P. Xie, "Volumetric fracturing behavior of $3 \mathrm{D}$ printed artificial rocks containing single and double 3D internal flaws under static uniaxial compression," Engineering Fracture Mechanics, vol. 205, pp. 190-204, 2019.

[18] M. Adams and G. Sines, "Crack extension from flaws in a brittle material subjected to compression," Tectonophysics, vol. 49, no. 1-2, pp. 97-118, 1978.

[19] X.-P. Zhou, J.-Z. Zhang, and L. N. Y. Wong, "Experimental study on the growth, coalescence and wrapping behaviors of 3D cross-embedded flaws under uniaxial compression," Rock Mechanics and Rock Engineering, vol. 51, no. 5, pp. 1379-1400, 2018.

[20] Y. Ju, C. Xi, Y. Zhang, L. Mao, F. Gao, and H. Xie, "Laboratory in situ ct observation of the evolution of 3D fracture networks in coal subjected to confining pressures and axial compressive loads: a novel approach," Rock Mechanics and Rock Engineering, vol. 51, no. 11, pp. 3361-3375, 2018.

[21] J. B. Zhu, T. Zhou, Z. Y. Liao, L. Sun, X. B. Li, and R. Chen, "Replication of internal defects and investigation of mechanical and fracture behaviour of rock using $3 \mathrm{D}$ printing and 3D numerical methods in combination with X-ray computerized tomography," International Journal of Rock Mechanics and Mining Sciences, vol. 106, pp. 198-212, 2018.

[22] J.-W. Fu, K. Chen, W.-S. Zhu, X.-z. Zhang, and X.-j. Li, "Progressive failure of new modelling material with a single internal crack under biaxial compression and the 3-D numerical simulation," Engineering Fracture Mechanics, vol. 165, pp. 140-152, 2016.

[23] A. V. Dyskin, E. Sahouryeh, R. J. Jewell, H. Joer, and K. B. Ustinov, "Influence of shape and locations of initial 3-D cracks on their growth in uniaxial compression," Engineering Fracture Mechanics, vol. 70, no. 15, pp. 2115-2136, 2003.

[24] L. N. Germanovich, R. L. Salganik, A. V. Dyskin, and K. K. Lee, "Mechanisms of brittle fracture of rock with preexisting cracks in compression," Pure and Applied Geophysics, vol. 143, no. 1-3, pp. 117-149, 1994.

[25] X. Li, Z. Zhou, T.-S. Lok, L. Hong, and T. Yin, "Innovative testing technique of rock subjected to coupled static and dynamic loads," International Journal of Rock Mechanics and Mining Sciences, vol. 45, no. 5, pp. 739-748, 2008.

[26] X. Li, F. Gong, J. Zhao, and K. Gao, "Test study of impact failure of rock subjected to one-dimensional coupled static and dynamic loads," Chinese Journal of Rock Mechanics and Engineering, vol. 29, no. 2, pp. 251-260, 2010. 
[27] F. Zhao, X. Li, T. Feng, and S. Xie, "Theoretical analysis and experiments of rock fragmentation under coupling dynamic and static loads," Chinese Journal of Rock Mechanics and Engineering, vol. 24, no. 8, pp. 1315-1320, 2005.

[28] Y. Zhou, S. Yin, and D. Zhao, "Effect of static loading on rock fragmentation efficiency under ultrasonic vibration," Geotechnical \& Geological Engineering, vol. 37, no. 4, pp. 34973505, 2019.

[29] D. Zhao, S. Zhang, and M. Wang, "Microcrack growth properties of granite under ultrasonic high-frequency excitation," Advances in Civil Engineering, vol. 2019, Article ID 3069029, 11 pages, 2019.

[30] Y. Zhou, D. Zhao, Q. Tang, and M. Wang, "Experimental and numerical investigation of the fatigue behaviour and crack evolution mechanism of granite under ultra-high-frequency loading," Royal Society Open Science, vol. 7, no. 4, Article ID 200091, 2020.

[31] Q. Tang, D. Zhao, Y. Zhou, and Z. Zhang, "Discrete element simulation for investigating fragmentation mechanism of hard rock under ultrasonic vibration loading," Energy Science \& Engineering, vol. 8, pp. 1-18, 2020.

[32] H. Li, S. Liu, Z. Zhu, H. Liu, D. Zhang, and C. Guo, "Experimental investigation on rock breaking performance of cutter assisted with hydraulic fracturing," Engineering Fracture Mechanics, vol. 248, Article ID 107710, 2021.

[33] Z. Jiang, S. Yu, H. Deng, J. Deng, and K. Zhou, "Investigation on microstructure and damage of sandstone under cyclic dynamic impact," IEEE Access, vol. 7, pp. 133145-133158, 2019.

[34] J. Zhang and Y. Li, "Ultrasonic vibrations and coal permeability: laboratory experimental investigations and numerical simulations," International Journal of Mining Science and Technology, vol. 27, no. 2, pp. 221-228, 2017.

[35] C. Wang, Z. Lu, L. Liu, X. Chuai, and H. Lu, "Predicting points of the infrared precursor for limestone failure under uniaxial compression," International Journal of Rock Mechanics and Mining Sciences, vol. 88, pp. 34-43, 2016.

[36] D. Zhao, S. Zhang, Y. Zhao, and M. Wang, "Experimental study on damage characteristics of granite under ultrasonic vibration load based on infrared thermography," Environmental Earth Sciences, vol. 78, no. 14, 2019.

[37] Y. Zhou, Q. Tang, S. Zhang, and D. Zhao, "The mechanical properties of granite under ultrasonic vibration," Advances in Civil Engineering, vol. 2019, Article ID 9649165, 11 pages, 2019. 